\title{
A influência dos investimentos em responsabilidade social sobre a imagem e a capacidade competitiva das organizações
}

\author{
Alano Nogueira Matias ${ }^{1}$ \\ Aguilar Ferrari²
}

\section{Resumo}

No século XX, o acesso à informação e o surgimento de novas tecnologias permitiram às empresas alcançarem maior produtividade, mas as transformações socioeconômicas fizeram aumentar a concorrência entre elas. Paralelamente, o enfraquecimento do Estado e o agravamento dos problemas sociais evidenciaram a importância das estratégias de desenvolvimento. Nesse contexto, percebeu-se que a exploração desordenada dos recursos naturais estabeleceu a obrigação de preservar as condições de vida na terra. Percebeu-se, então, a necessidade das organizações atuarem dentro de princípios morais e agirem respeitando o direito, os valores e os interesses daqueles que serão influenciados por suas ações ou atividades produtivas. Emergia um paradigma da nova ordem social, no qual se priorizam atividades de interesses coletivistas para amenizar as mazelas sociais. Trata-se do surgimento da consciência social por parte das organizações, quando se percebe que a disparidade é prejudicial ao desenvolvimento econômico. $\mathrm{O}$ resultado foi uma adaptação da lógica racional do sistema produtivo, inserindo nele a racionalidade social, cujo objetivo era minimizar os efeitos indesejáveis da globalização e os riscos sistêmicos. Gradativamente, as organizações assumem a condição de agentes de desenvolvimento, sem descaracterizar o papel do Estado e da sociedade. Os modelos de gestão de conduta responsável, voltados para o atendimento das demandas da sociedade, e a conciliação deles com a estratégia do negócio surgem como formas inovadoras de alcançar melhoria da imagem, de aumentar o market share das organizações e apresentam-se como procedimentos viáveis para gestão de negócios lucrativos, de impactos positivos e benéficos para todos os agentes envolvidos.

1 Doutor em Administração e Coordenador do Curso de Administração do UNICESP.

2 Estudante do $8^{\circ}$. semestre do curso de administração do Centro Universitário de Brasília - UniCEUB. 
Palavras-chave: Responsabilidade social. Desenvolvimento. Competitividade. Ética. Estratégia. Melhoria da imagem. Impactos positivos.

\section{Introdução}

Ao longo do século XX, a competitividade das organizações era definida pela capacidade de produzir com menor custo e praticar preços mais baixos. $\mathrm{O}$ acesso à informação e o surgimento de novas tecnologias permitiram às empresas aumentar a produtividade, mas as transformações socioeconômicas, a complexidade dos mercados e o advento da globalização fizeram aumentar em grandes proporções a concorrência entre elas, tornando nítida a necessidade de se buscar formas inovadoras de participação no mercado.

Nesse mesmo período, a perda de força por parte do Estado e o agravamento dos problemas sociais, como a proliferação da miséria e da fome, o desemprego, a discriminação, a escalada da violência, a desconstrução do caráter e o crescimento da desigualdade, associados à flagrante incapacidade das instituições públicas para encontrar soluções rápidas e eficientes para tais problemas, revelou à sociedade que o crescimento sustentado requer bases sólidas, evidenciando a importância de se repensar o desenvolvimento econômico, social e ambiental (ASHLEY, 2002, p. 3), por intermédio da busca de soluções corretas e viáveis.

Tamanha força opressiva resultou em uma adaptação da lógica racional do sistema produtivo, baseado na ordem econômica dominante, inserindo nele a racionalidade social, cujo advento não objetivava paralisar o processo de globalização, mas sim atenuar os seus efeitos indesejáveis e minimizar os riscos sistêmicos. De acordo com Melo Neto e Froes (2001) tal perspectiva gradativamente elevou as organizações à condição de investidores sociais e agentes de desenvolvimento de primeira grandeza, sem, entretanto, descaracterizar o papel do Estado e da própria sociedade nesse processo.

Importante observar que emerge um paradigma da nova ordem social, o qual requer a empatia de todos os agentes correlacionados, ou seja, somente o 
comprometimento de pessoas, empresas e governos dispostos a trabalhar em favor da priorização de atividades de interesses coletivistas pode garantir que essa nova tendência mundial alcance êxito e produza resultados satisfatórios e amenizadores das mazelas sociais.

Este trabalho tem como finalidade evidenciar a importância da integração dos investimentos em responsabilidade social à estratégia do negócio, por meio da adoção de ações éticas nas relações empresariais, da solidariedade como forma de criar uma sociedade mais justa e de práticas sustentáveis em relação ao meio ambiente, e a sua influência sobre a imagem e a capacidade competitiva das organizações.

Utilizou-se o método qualitativo de abordagem e foi feita pesquisa bibliográfica valendo-se de dados secundários, como livros, artigos científicos e sites relacionados para levantamento de relatos, pontos de vista e informações, exemplificação com situações concretas e demonstração de resultados potenciais e efetivos, como benefícios gerados e vantagens mercadológicas alcançadas, envolvendo as práticas mais comuns dentro das organizações que investem em responsabilidade social corporativa e cidadania empresarial.

O instrumento adotado teve como objetivo identificar relatos e trabalhos de pesquisa de autores que demonstrem vantagens ou resultados positivos para as organizações, assim como benefícios para a sociedade e para o meio ambiente, decorrentes da adoção de práticas socialmente elogiáveis.

Justificou-se a realização deste trabalho pela expectativa de ampliação do conhecimento sobre um tema de relativo interesse no meio acadêmico e que, cada vez mais, tem se tornado objeto de debates da comunidade científica internacional, haja vista o grande número de eventos, seminários e prêmios relacionados ao tema. Observa-se, ainda, tratar-se de assunto de destaque e importância estratégica no meio empresarial.

A justificativa aplicada apoiou-se no entendimento sobre o conceito e os verdadeiros fundamentos da responsabilidade social, especialmente no que se refe- 
re aos benefícios gerados e vantagens competitivas obtidas pelas organizações que desenvolvem estas ações.

Adicionalmente, a justificativa social é de que este trabalho aprofundou-se na análise de práticas que contribuem para a melhoria da qualidade de vida da sociedade e para a sustentabilidade do meio ambiente, assim como podem significar estratégia de crescimento e ampliação do market share e do customer share de uma organização.

Embora Ashley (2002) considere que a primeira responsabilidade social de uma organização deveria ser com o seu quadro de empregados e que seria uma grande incoerência desenvolver projetos assistencialistas sem antes cuidar de sua própria força de trabalho, para efeito de delimitação do escopo da pesquisa bibliográfica, sem desconsiderar a importância de cada um dos vetores que caracterizam as ações de responsabilidade social, neste trabalho não se pretende aprofundar o debate sobre vertentes como benefícios para o quadro de funcionários, escala de clima organizacional e nível de satisfação de clientes, entre outras. Dessa forma, apenas três aspectos serão considerados: a ética empresarial como pilar básico de estabelecimento da estratégia do negócio, as ações de sustentabilidade e preservação do meio ambiente e a solidariedade em favor dos públicos com os quais as organizações interagem, a qual resulta no compromisso com a construção de uma estrutura social menos desigual.

Ao final, espera-se que tenha sido possível: contribuir para estabelecer uma nomenclatura simplificada, esclarecedora e convergente sobre os conceitos de responsabilidade social corporativa, responsabilidade social empresarial, ética empresarial e cidadania empresarial; descrever a importância dos investimentos em responsabilidade social como mecanismo de diminuição das disparidades e instrumento para o desenvolvimento de relações duradouras e de confiança; valorizar a prática de ações de responsabilidade social, as quais elevam uma empresa ao patamar de organização responsável; e demonstrar se os investimentos em responsabilidade social resultam em benefícios para as organizações, como a solidificação da imagem e a obtenção de vantagens e diferenciais competitivos. 


\section{Referencial teórico}

Inicialmente, serão identificadas as semelhanças e divergências nas diferentes abordagens dos conceitos de responsabilidade social corporativa e cidadania empresarial, de forma a contribuir para o seu tratamento teórico e aplicação prática, com base na análise conceitual de Ashley (2002) e do Instituto Ethos de Empresas e Responsabilidade Social (2003).

Na sequência, será destacada a importância da ética e da transparência nos negócios, e do comprometimento para a criação de uma sociedade melhor e mais justa, segundo as argumentações de Trasferetti (2006), do Instituto Ethos (2003), de Lourenço e Schroder (2003) e de Fedato (2005).

Prosseguindo, será interpretada a preocupação com a preservação do meio ambiente e analisada a sua relevância, com base nas contribuições de Trasferetti (2006), de Melo Neto e Froes (2001) e da Fundação Orsa (2009).

A seguir, a abordagem apresentará argumentações contrárias e favoráveis à prática de ações de responsabilidade social, evidenciando o quanto essa nova ordem mundial vem sendo valorizada por todos os públicos que mantêm relações com as organizações e a eficácia dessas ações enquanto estratégia de competitividade e de prestígio no meio empresarial, tendo como base os dados do IPEA e os trabalhos de Ashley, Coutinho e Tomei (2000), de Cheibub e Locke (2000), de Melo Neto e Froes (2001), de Coutinho e Macedo-Soares (2002) e de Lourenço e Schroder (2003).

Apresenta-se, então, a realidade dos investimentos em responsabilidade social no Brasil apoiada em informações do IBASE, do GIFE e do IPEA e contextualizam-se as expectativas do mercado e o comportamento do consumidor, com base nos dados de pesquisas do Instituto Ethos e do BSR - Bureau for Social Responsibility, da Revista Carta Capital e nos relatos de Coutinho e Macedo-Soares (2002) e de Melo Neto e Froes (2001).

Por fim, articula-se a discussão dos dados das pesquisas realizadas pelo IPEA, pelo CEATS-USP e pelo Instituto Ethos, além das considerações de Lourenço e Schroder (2003) e de Fedato (2005). 


\subsection{Contexto histórico da responsabilidade social}

Apesar da vasta literatura existente, conforme citações no parágrafo anterior e também a seguir, Ashley (2002) menciona que as variáveis idiomáticas acerca do tema, como as expressões responsabilidade social corporativa, responsabilidade social empresarial, ética empresarial e cidadania empresarial, por vezes são apresentadas de forma pouco didática e eventualmente de maneira contraditória. A autora propõe a divisão do conceito em duas fases distintas: a incorporação do tema nos meios acadêmico e empresarial, até meados do século XX, e sua evolução mais recente, a partir da década de 60 até este início de século XXI.

Acerca da análise conceitual e da aplicação da responsabilidade social, a bibliografia consultada registra relevantes contribuições desenvolvidas por Friedman (1970), Freeman e Lietka (1991) e Jones (1996), que esclarecem a argumentação contrária à prática dessas ações e explicam a defesa da relação de causalidade negativa entre os investimentos em responsabilidade social e a performance financeira das organizações. Em oposição, os discursos de Carroll (1991), de Wood Júnior (2001), de Donaldson e Dunfee (1994), de Frederick (1994), de Maignan (1999) e de Davenport (2000) consideram a atuação social não apenas uma postura restauradora da ética da responsabilidade por parte das organizações, como também visualizam os diferenciais competitivos que podem advir dessa prática.

Não se consegue ter uma perspectiva clara do que efetivamente caracteriza a responsabilidade social corporativa e a cidadania empresarial, se não se considerar que a abordagem pode ser feita pela ótica do consumidor, das empresas, do governo ou da sociedade. De fato, o conceito envolve posturas, comportamentos, atitudes e ações que influenciam positivamente uma comunidade, o meio ambiente ou a sociedade, e tem significado bastante amplo, que tende a variar conforme a circunstância e de acordo com o conhecimento e as expectativas de cada indivíduo. De uma maneira geral, os relatos bibliográficos conduzem a interpretações múltiplas, como caridade, uma obrigação legal ou função social por parte das organizações, exigindo delas um padrão de comportamento diferenciado em relação ao cidadão comum (ASHLEY, COUTINHO e TOMEI, 2000), a adoção de 
princípios éticos na tomada de decisão e os valores que definem as prioridades das organizações (INSTITUTO ETHOS..., 2003), a contraposição do individualismo, da competição, da deterioração e da desigualdade à coesão social, à solidariedade, à cooperação e à participação (MELO NETO; FROES, 2001), entre outras.

Nesse contexto de consolidação do conceito, as terminologias passaram a ser acompanhadas por siglas: responsabilidade social corporativa (CSR1); responsabilidade social corporativa com foco gerencial (CSR2), enfatizando a gestão das relações entre empresa e sociedade; retidão social corporativa (CSR3), incorporando uma ética normativa, ao propor padrões recomendáveis de comportamento social nas relações entre empresas e sociedade; e desempenho social corporativo (CSP), com maior orientação para resultados e foco no impacto dos negócios para a sociedade (FREDERICK, 1994 apud COUTINHO; MACEDO-SOARES, 2002).

Independentemente da segmentação e das nomenclaturas resumidas, observa-se que os conceitos apresentam alguma convergência e os objetivos são sempre estabelecidos, visando ao atendimento das expectativas dos stakeholders, ou seja, das partes interessadas com as quais as organizações interagem, seja de forma direta ou indireta. Esse ponto de vista será instrumentalizado ao longo desse estudo bibliográfico para que se possa alcançar a resposta ao problema de pesquisa apontado.

Assim, considerando que as definições do tema central deste trabalho ainda se encontram em construção, adotar-se-á resumidamente as terminologias responsabilidade social e responsabilidade social corporativa, podendo ser representadas pela sigla RSC e, de acordo com o contexto, podendo significar "os critérios éticos que as empresas utilizam para a tomada de decisões, os valores que definem suas prioridades" (INSTITUTO ETHOS..., 2003), “o relacionamento com todos os públicos com os quais interagem, as responsabilidades para com a construção de uma sociedade menos desigual, as obrigações para com o meio ambiente" (ASHLEY, 2002, p. 7), e "a ação voluntária em favor de causas públicas, em benefício da sociedade ou do meio ambiente" (MELO NETO; FROES, 2001, p. 19). 


\section{2 Ética empresarial}

O Instituto Ethos (2003) considera que o comportamento ético nos negócios pode ser medido quando as decisões que dizem respeito à determinada empresa levam em consideração o direito, os valores e os interesses de todos aqueles que serão afetados por suas ações. Defende, ainda, que uma empresa não estará sendo ética se, no desenvolvimento de suas atividades produtivas, não se preocupar, por exemplo, com a poluição que gera no meio ambiente, ainda que ofereça um produto de excepcional qualidade e de padrão superior ao dos concorrentes.

Para Trasferetti (2006), a ética sugere responsabilidades que devem incluir tudo que se refere à existência humana. Neste início de século XXI, o autor considera imprescindíveis a análise das relações sociais, a compreensão dos compromissos éticos e a necessidade de agir dentro de princípios morais que estabeleçam responsabilidades que permeiem todas as questões relativas à humanidade, desde a tolerância à ética da convivência até a necessidade de se cuidar da ecologia.

A postura ético-empresarial é também abordada por Melo Neto e Froes (2001), que observam que tal comportamento deve privilegiar relações confiáveis e duradouras com todos os segmentos relacionados à organização: parceiros, governo, meio ambiente, consumidores, concorrentes, comunidade e sociedade global. Ao atuar de maneira socialmente responsável, uma empresa é capaz de adotar, difundir e transferir valores éticos aos cidadãos. "A dimensão ética ganhou tal importância no âmbito da responsabilidade social corporativa, que hoje é possível proceder a uma avaliação específica do que denominamos 'comportamento ético-social da empresa” (MELO NETO; FROES, 2001, p. 134).

Na linha instrumental, Lourenço e Schroder (2003) observam que os padrões éticos de comportamento impõem às organizações limitações no sentido de realizar ações imorais e ilícitas para obtenção de vantagem competitiva ou que objetivem o enfraquecimento ou a desarticulação dos concorrentes. Práticas como concorrência desleal, difamação, sabotagem, espionagem industrial e hunting junto à concorrência para obter acesso a informações privilegiadas devem ser combatidas a qualquer custo. 
A discussão é enriquecida por Fedato (2005), ao afirmar que, apesar da responsabilidade ética não ser uma exigência, é desejado pela sociedade que os princípios morais de uma organização estejam de acordo com a cultura social vigente na comunidade onde ela está inserida.

\subsection{Responsabilidade ambiental}

Durante a maior parte do século XX, deu-se pouca importância ao meio ambiente e esqueceu-se que o ser humano é parte inseparável dele. As necessidades humanas são infinitas e os danos quase irreversíveis ocasionados pela exploração desordenada dos recursos naturais, à beira da exaustão, culminaram com a obrigação urgente de poupar o planeta de catástrofes da natureza que impossibilitem a existência de vida humana em sua superfície (TRASFERETTI, 2006).

Como resultado dessas preocupações, Melo Neto e Froes (2001) analisam que a gestão ambiental deve obedecer três critérios básicos, que seriam a realização de ações de capacitação de recursos humanos, a integração das ações de preservação ambiental com as ações de saúde e segurança industrial e a certificação ambiental com base nas normas ISO 14000 e BS 8800. Os autores defendem que uma empresa ambientalmente responsável destaca-se pela excelência ambiental, pela atuação enquanto agente de desenvolvimento sustentável regional, pela preservação da saúde, da segurança e da qualidade de vida da comunidade onde atua e pela formalização do compromisso com a questão ambiental expressado por intermédio de sua missão, de sua visão e de seus valores.

No sentido de estimular práticas de gestão socialmente elogiáveis, uma iniciativa pioneira e que pode gerar resultados positivos é a criação do Selo Verde. Idealizado em 2009 pela Fundação Orsa, uma instituição sem fins lucrativos. O Selo Verde é o reconhecimento para ambientes digitais baseado no conceito internacional dos três Ps - People (Pessoas), Profit (Lucro) e Planet (Planeta). A conquista do selo por uma organização social, órgão governamental ou empresa privada significa que o ambiente digital de reconhecimento está dentro dos crité- 
rios que equilibram os pilares norteadores da sustentabilidade: socialmente justo, economicamente viável e ambientalmente correto.

À questão ambiental, cabe a associação com o conceito de externalidades, que são atividades relacionadas à ação involuntária de fatores que podem ocasionar efeitos positivos ou negativos a terceiros, sem que eles possam desenvolver qualquer tipo de ação preventiva ou requerer seus direitos. Assim, toda e qualquer iniciativa empresarial de preservação do meio ambiente seria designada como externalidade positiva, pois beneficia toda a sociedade sem lhe impor qualquer ônus, enquanto a poluição ambiental ocasionada pelas atividades produtivas inseguras seria classificada como externalidade negativa.

\subsection{Importância e aplicação da responsabilidade social}

O surgimento da consciência social por parte das organizações se dá em um contexto de adversidade, quando se percebe, segundo Melo Neto e Froes (2001), que o enfraquecimento do poder de compra dos consumidores, a deficiência nos sistemas educacionais e o crescimento da disparidade social são prejudiciais também à expectativa de desenvolvimento econômico das organizações. Assim, a preocupação com as ações filantrópicas e assistencialistas, que parecia esquecida ou relegada ao segundo plano, ressurge travestida de modelos de empreendedorismo social e de filantropia de alto desempenho, especialmente quando as empresas começam a perceber ganhos expressivos de imagem.

A ideia da RSC incorporada aos negócios recebeu os maiores impulsos a partir da década de 1990. Desde então, o tema tem merecido atenção dos consumidores e do mercado, o que estimula as empresas a adotarem posturas mais responsáveis em suas ações, com intuito de melhorar a imagem e estabelecer diferenciais mercadológicos. Em uma análise simplificada, Ashley (2002) considera que a RSC é isto: toda e qualquer ação que resulta em melhoria da qualidade de vida da sociedade. De fato, a preocupação com os interesses da coletividade é atitude ética e socialmente responsável e a promoção do bem comum, segundo Trasferetti (2006), apresenta-se como uma das mais altruístas e elogiáveis atitudes no campo da cidadania empresarial. 
Diante de tais constatações, a responsabilidade social corporativa pode ser analisada e compreendida como questão de natureza estratégica, uma maneira inovadora de obtenção de lucros e de busca do desenvolvimento sustentável, que pode ser implementada no sentido de agregar valor à estratégia do negócio, em conjunto com outros princípios de gestão conhecidos pela inteligência empresarial. As expectativas do mercado e do público consumidor estão receptivas a esse tipo de comportamento, portanto não se pode desconsiderar que essa motivação seja uma boa justificativa para que as instituições promovam esse tipo de atividade.

As motivações podem ser de cunho legal, político, social, moral, ético ou religioso, mas, independentemente da natureza, as discussões sobre a importância, a viabilidade e o verdadeiro papel da responsabilidade social integrada à estratégia do negócio, ganham importância, geram um crescente interesse por parte da sociedade e alcançam a esfera da alta administração empresarial. Sabe-se que a curiosidade e o interesse conduzem ao aprendizado e ao conhecimento, mas, à medida que se amplia o debate, surgem também as divergências de pontos de vista. E a boa fundamentação de ambas as correntes de pensamento, igualmente bem articuladas, pode conduzir a conclusões conflitantes.

Cheibub e Locke (2000) propõem que a discussão deve basear-se em empresas que assumem responsabilidades além daquelas exigidas por lei. Não se pode considerar como socialmente responsável um agente que apenas obedece à legislação ou acorda benefícios em negociações trabalhistas. Responsabilidade social significa muito mais. Melo Neto e Froes (2001) afirmam que uma organização socialmente responsável torna-se cidadã porque dissemina valores que priorizam o compromisso social, a equidade e a dignidade, e apontam que a atuação responsável é caracterizada por ações que desenvolvam a cultura da sustentabilidade, além de representar uma contribuição direta para a diminuição das dificuldades enfrentadas pelas classes menos favorecidas.

Dentre os argumentos contrários à RSC, destaca-se a explicação de Jones (1996 apud ASHLEY, 2002) sobre o conceito de direitos de propriedade, no qual prevalece como objetivo primário das organizações a maximização dos lucros, resguardando assim o interesse dos acionistas. Dentro dessa ótica, não seria das 
corporações privadas a responsabilidade legal ou moral de cumprir com obrigações sociais, diferentemente de outras instituições, como o governo, a igreja e as organizações sem fins lucrativos, a quem caberia tal atribuição, uma vez que hipoteticamente teriam sido criadas para isso.

Dentro da visão produtivista, Friedman (1970 apud COUTINHO; MACEDO-SOARES, 2002) justifica que a falta de comprovação da influência direta da atuação socialmente responsável na performance econômica de uma organização conduz à defesa da relação de causalidade negativa entre investimento social e desempenho financeiro, já que as empresas socialmente responsáveis estariam em desvantagem competitiva, em razão do aumento de custos que não poderiam ser transferidos para os preços dos produtos.

Em contrapartida, Waddock e Graves (1997 apud COUTINHO; MACEDO-SOARES, 2002) realizaram testes empíricos utilizando medidas de desempenho financeiro (retorno sobre ativos, sobre patrimônio líquido e sobre vendas) para demonstrar que a maior participação social parece estar positivamente ligada ao desempenho financeiro favorável, independentemente de qual das duas dimensões - social ou financeira - é utilizada como variável dependente.

Em outro estudo mencionado por Coutinho e Macedo-Soares (2002) acerca da reputação associada ao valor de uma empresa, Tiras, Ruff e Brown (1998) constataram maiores coeficientes de avaliação para empresas cotadas como "boas" na classificação KLD (Kinder, Lyndenberg, Domini) de desempenho social. Contudo, os resultados foram conclusivos apenas para três dos quatro grupos de stakeholders: empregados, consumidores e meio ambiente; com resultado inconclusivo para comunidade.

Nota-se que até o fim da década de 1990, as pesquisas, como as mencionadas sobre os benefícios para as empresas não eram conclusivas quanto ao interesse delas em praticar ações de RSC. Cheibub e Locke (2000) concluíram, então, que um dos argumentos utilizados pelos produtivistas é de que se um investimento não traz retorno econômico para a empresa, ela não estaria cumprindo sua função social de usar todos os meios lícitos e legais para ser a mais produtiva possível. Assim, 
do ponto de vista do investimento, os estudos empíricos ainda não eram suficientes para prover argumentos contrários à visão produtivista.

Pelo lado da proposição favorável à atuação social, Swanson (1995 apud ASHLEY; COUTINHO; TOMEI, 2000) propõe aperfeiçoamento do modelo desenvolvido por Wood Júnior (2001), integrando as perspectivas econômicas e normativas aos princípios de RSC. Pela incorporação da ética e dos valores nas relações de troca dos processos sociais e decisórios, os princípios de responsabilidade social corporativa nos níveis individual, organizacional e institucional se ampliariam além das considerações de trocas materiais da corporação.

Tal argumentação reforça o ponto de vista de uma área conhecida como business and society (negócios e sociedade). Dentro dessa linha de pensamento, Carroll (1991) defende que uma empresa-cidadã deve ser lucrativa, obedecer às leis, ter comportamento ético, seguindo padrões moralmente aceitos nas sociedades em que atua, e praticar a filantropia.

Cheibub e Locke (2000) vão além, sustentando que as empresas têm uma espécie de obrigação moral perante a sociedade, a qual permite que elas exerçam atividades produtivas, e que devem fazer com que seus benefícios e matérias de sua ação atinjam a todos os setores da sociedade, assumindo um papel ativo para a resolução dos problemas sociais e determinante na construção de uma hierarquia social menos perversa. Os mesmos autores ponderam ainda que os benefícios diretos que as empresas possam auferir com a prática social sejam de difícil mensuração, promovê-las é do seu interesse esclarecido e de longo prazo.

Demonstrando a importância atribuída à RSC pela classe empresarial, Passos (2002 apud LOURENÇO; SCHRODER, 2003) relata que em 2002, no Fórum Econômico Mundial, realizado em Nova York, foi apresentado resultado de pesquisa de opinião realizada pela empresa de consultoria PricewaterhouseCoopers, "que ouviu 1.161 executivos de empresas europeias, asiáticas e americanas, onde $68 \%$ deles concordava que a RSC era vital para a lucratividade da empresa, e 60\% considerava que mesmo com clima econômico desfavorável não se deveria diminuir a prioridade nesses investimentos". 
Percebe-se, portanto, que a RSC não é meramente uma questão moral, e sim um interesse econômico e fator de diferenciação para as empresas. Cheibub e Locke (2000) defendem que as empresas devem ter responsabilidades sociais apenas se for conveniente ao seu negócio e gerar benefícios para sua atividade produtiva ou posicionamento no mercado. Assim sendo, quanto mais interesses tiverem, mais funções devem assumir.

Um modelo de representação gráfica em forma de pirâmide, desenvolvido por Carroll (1991), apresenta os níveis em que as organizações deveriam concentrar sua atuação. Na base está a responsabilidade econômica e, no topo, a responsabilidade discricionária. A pirâmide de Carroll divide-se em três dimensões de responsabilidades: obrigatórias, desejáveis e subjacentes.

Figura 1 - Pirâmide da responsabilidade social corporativa.

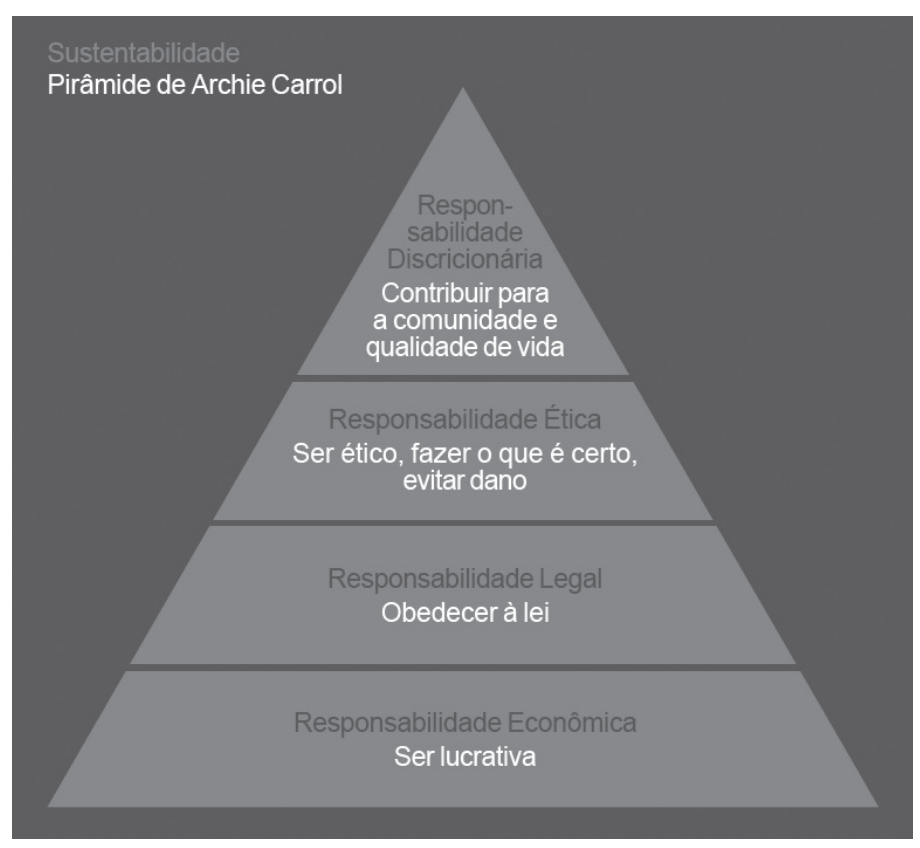

Fonte: Informativo CEO Brasil, ano 1. n. 2, out./dez. 2004. PricewaterhouseCoopers. Adaptado de Archie B. Carroll (1991).

A seguir, serão apresentadas evidências de que empresas que privilegiam comportamento responsável alcançam maiores benefícios do que as que não o fa- 
zem. Essa seria, portanto, uma explicação plausível para que as organizações implementem políticas de responsabilidades além das que estão previstas em lei.

\subsection{A realidade brasileira}

O trabalho desenvolvido pela organização não governamental Instituto Brasileiro de Análises Sociais e Econômicas (IBASE, 2010) é um dos expoentes da ação social no Brasil. Um dos marcos de grande repercussão e propulsor da consciência social no Brasil ocorre em 1993, quando é lançada a Campanha Nacional da Ação da Cidadania Contra a Fome, a Miséria e pela Vida, idealizada pelo sociólogo Herbert de Souza, o Betinho, fundador do IBASE e um dos ícones da luta pela diminuição do abismo social entre as classes mais pobres e as mais bem sucedidas da população. O IBASE é também responsável pela criação e legitimação do Balanço Social, uma espécie de relatório demonstrativo publicado anualmente contendo informações sobre projetos, benefícios e ações sociais.

Em 1995, foi instituído o GIFE - Grupo de Institutos Fundações e Empresas, uma rede sem fins lucrativos que reúne organizações de origem empresarial, familiar, independente e comunitária, que investem em projetos com finalidade pública. Sua missão é aperfeiçoar e difundir conceitos e práticas do uso de recursos privados para o desenvolvimento do bem comum, contribuindo assim para a promoção da sustentabilidade do Brasil, por meio do fortalecimento político-institucional e do apoio à atuação estratégica dos investidores sociais privados.

A partir da aproximação das instituições com as ações sociais e da adesão de lideranças setoriais, o Brasil passa a apresentar significativo crescimento do movimento da responsabilidade social corporativa.

De acordo com dados da Pesquisa Ação Social das Empresas, realizada pelo Instituto de Pesquisa Econômica Aplicada (IPEA), entre os anos de 2000 e 2004, houve um aumento de 10 pontos percentuais na proporção de empresas privadas brasileiras que realizaram ações sociais em benefício das comunidades. "Neste período, a participação empresarial na área social aumentou de 59\% para 69\%. Isto 
significa que aproximadamente 600 mil empresas desenvolvem ações de voluntariado. Em termos de valores, elas aplicaram cerca de $\mathrm{R} \$ 4,7$ bilhões, o que correspondia a $0,27 \%$ do PIB brasileiro da época". Os dados correspondem à segunda edição da pesquisa e, a partir de então, o IPEA considera ser possível iniciar a construção de uma série histórica com objetivo de mapear e acompanhar a evolução do comportamento da iniciativa privada na área social a partir do final da década de 90 .

\subsection{Expectativa do mercado e comportamento do consumidor}

Mudanças nas relações comerciais envolvendo empresas com atuação social foram observadas e relatadas por Coutinho e Macedo-Soares (2002). Segundo os autores, ficou evidenciado um aumento no poder de barganha das empresas junto aos seus fornecedores, os quais desejavam vincular sua marca à imagem de uma organização admirada pelo mercado e reconhecida como socialmente responsável.

O Instituto Ethos (2003) afirma que já é representativo o número de médias e grandes empresas que selecionam fornecedores por meio de critérios da responsabilidade social nos negócios. No acesso aos créditos e financiamentos, também é crescente a adoção de critérios de gestão ambiental. Aplicação prática semelhante é descrita por Melo Neto e Froes (2001), ao afirmarem que os bancos passaram a obter lucratividade mediante o financiamento de projetos com o selo da responsabilidade social.

Melo Neto e Froes (2001) desenvolveram um modelo para analisar os padrões de conduta empresarial baseado em três variáveis: responsabilidade social interna (relações com empregados e seus dependentes), responsabilidade social externa (relações com a comunidade) e sucesso empresarial. 
Figura 2 - Responsabilidade social e sucesso empresarial.

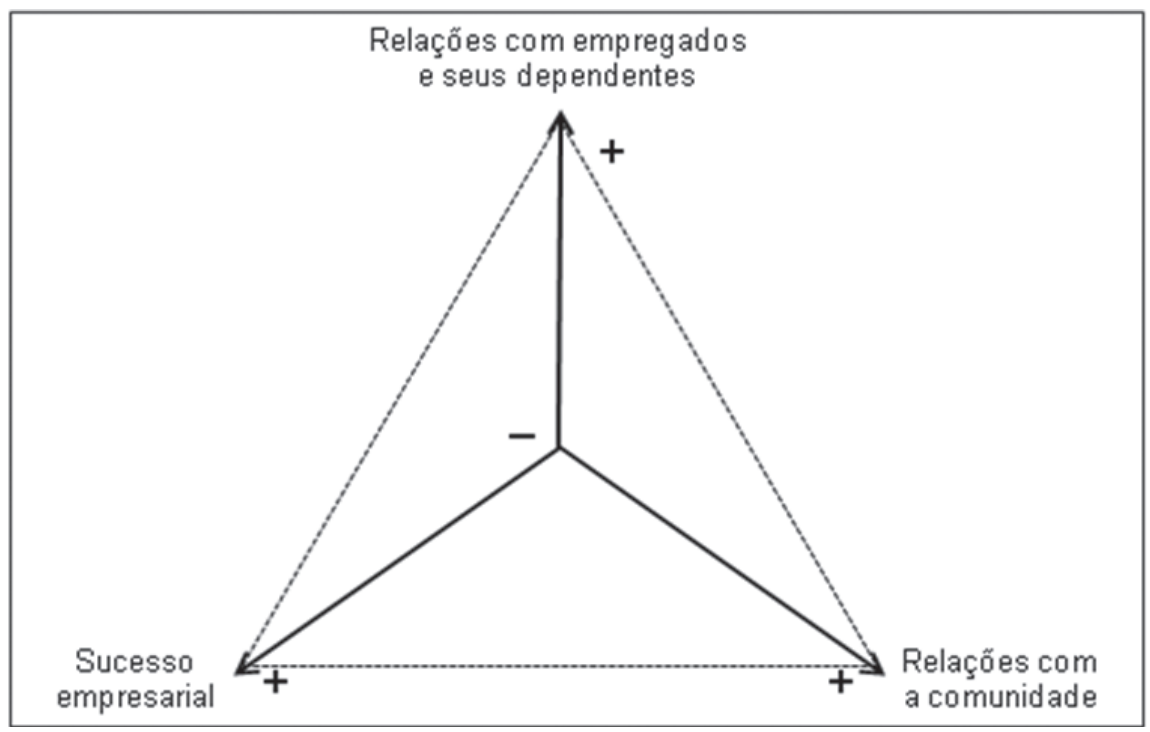

Fonte: Melo Neto e Froes (2001, p. 95). Gestão da responsabilidade social corporativa: o caso brasileiro.

O modelo aponta três padrões que resultariam em sucesso empresarial: a) atuação social voltada para o estreitamento das relações com a comunidade e com os empregados e seus dependentes; b) atuação social voltada exclusivamente para o estreitamento das relações com os empregados e seus dependentes; e c) atuação social voltada exclusivamente para o estreitamento das relações com a comunidade.

Contudo, gerenciamento de estratégias de ação social desequilibradas, segundo os autores, poderia resultar em insucesso por seleção equivocada de parceiros externos para projetos sociais, por escolha errada e gestão ineficaz da política de benefícios para os parceiros internos ou mesmo por desmotivação e insurgência dos empregados quando a organização privilegia as relações com os públicos externos. Observa-se, assim, o importante papel do capital humano, que é o elemento responsável pela produtividade e o principal insumo para alcance dos objetivos das organizações.

Compreende-se que as empresas com gestão consciente tendem a alcançar maior clareza quanto à própria missão. Sustentadas por essa compreensão, elas 
conseguem melhor ambiente de trabalho, maior grau de satisfação, motivação, interesse e comprometimento de seus funcionários, relações mais consistentes com fornecedores e clientes e melhor imagem na sociedade (INTITUTO ETHOS..., 2006). Evidentemente que esses são fatores que contribuem para a sobrevivência e o crescimento das empresas, aumentando o potencial de sucesso e de longevidade dos seus negócios.

Solucionadas as questões de caráter interno, analisa-se a preferência dos consumidores em privilegiar produtos e práticas que gerem benefícios para o meio ambiente ou a sociedade. Fabricar produtos que não degradem o meio ambiente, promover a inclusão social e participar do desenvolvimento da comunidade da qual fazem parte são ações percebidas como diferenciais competitivos para as empresas na conquista de novos clientes, segundo o Instituto Ethos (2006).

Tal afirmativa é evidenciada pela "Pesquisa 2006-2007 - Responsabilidade Social Empresarial - Percepção do Consumidor Brasileiro”, realizada pela Market Analysis Brasil, sob a supervisão do Instituto Akatu pelo Consumo Consciente e do Instituto Ethos de Empresas e Responsabilidade Social, na qual pelo menos $63 \%$ dos consumidores declararam predileção e maior respeito por empresas que desempenham papéis sociais. Tendência semelhante já havia sido apontada pelo BSR - Business for Social Responsibility, organização sem fins lucrativos de origem norte-americana, que tem sua atuação voltada para a divulgação de indicadores de responsabilidade social nos negócios.

Seguindo a mesma linha de investigação, analisa-se a $12^{a}$ edição da pesquisa As Empresas Mais Admiradas no Brasil, realizada em 2009 pela revista Carta Capital, com objetivo de premiar e destacar as empresas que constroem a respeitabilidade corporativa e contribuem para a difusão da ética empresarial e para o desenvolvimento socioeconômico do país, que apresentou o seguinte resultado:

$$
\begin{aligned}
& \text { 1\%. lugar: Natura; } \\
& \text { 2. lugar: Vale; } \\
& \text { 3. lugar: Petrobras; } \\
& \text { 4. lugar: Nestlé; }
\end{aligned}
$$




\section{0. lugar: Apple; \\ 6․ lugar: Google; \\ $7^{\circ}$. lugar: Itaú; \\ $8^{\circ}$. lugar: Gerdau; \\ $9^{\circ}$. lugar: AmBev; \\ $10^{\circ}$. lugar: Embraer}

A pesquisa, realizada nos meses de julho e agosto de 2009, entrevistou 1238 executivos de 42 setores da Economia. Independentemente do setor, os critérios para a eleição foram baseados em 12 fatores-chave, entre eles, qualidade de produtos e serviços, responsabilidade social, comprometimento com o desenvolvimento sustentável, ética e respeito pelo consumidor.

Observa-se que todas as empresas listadas mantêm programas estruturados e atuam em alguma das dimensões da responsabilidade social. Portanto, as estatísticas apresentadas sugerem que quem privilegia a ética, a solidariedade e a consciência ecológica, constitui uma imagem de competência empresarial, conquista o respeito do consumidor, a admiração da sociedade e cria condições favoráveis para ampliar a sua participação no mercado.

Por isso, as organizações precisam investir no aperfeiçoamento permanente de suas relações com todos os públicos com os quais se relacionam, a começar pela comunidade onde está inserida, mas sem perder de vista a sociedade em geral, que é construída e delineada a cada dia. Com efeito, trata-se de ações com objetivos amplos, ligados aos interesses de ordem moral e de valor das empresas, atendendo aos seus objetivos imediatos ou de longo prazo (CHEIBUB; LOCKE, 2000).

\section{Resultados e discussão}

Os estudos de Cheibub e Locke (2000) apontam que não existem argumentos morais suficientes para justificar que as empresas devam ser socialmente mais responsáveis que qualquer outro ator social. A promoção das ações é, antes de tudo, uma iniciativa de interesse das organizações, visto que elas não podem se 
apropriar de lucros e vantagens imediatas ao se engajarem em atividades sociais, mas em médio e longo prazo elas se beneficiam dos resultados dessa prática.

Indícios nesse sentido foram apontados pela segunda edição da Pesquisa Ação Social das Empresas, realizada pelo IPEA, que revelou que, na percepção dos empresários brasileiros, a atuação social proporciona benefícios para todos os agentes, a saber:

- "Para 61\% dos executivos, houve aumento da satisfação pessoal e espiritual dos donos das empresas;

- $55 \%$ deles compreenderam que houve melhoria na qualidade de vida da comunidade;

- $40 \%$ observaram melhoria na relação da empresa com a comunidade;

- $26 \%$ relataram melhoria na imagem da empresa; e

- $24 \%$ notaram maior envolvimento e comprometimento dos funcionários com a empresa”.

O dado mais relevante, entretanto, diz respeito ao grau de insatisfação com os resultados obtidos. Apenas 4\% do universo pesquisado declaram que a não obtenção do retorno esperado configura um impedimento para a expansão da atuação social.

Além dessa pesquisa, levantamento realizado em 1999 pelo Centro de Empreendedorismo Social e Administração do Terceiro Setor (CEATS-USP),

[...] envolvendo 273 companhias estatais e privadas, de pequeno, médio e grande porte, localizadas em nove estados e no Distrito Federal, concluiu que o investimento em ações sociais melhorou em $79 \%$ a imagem institucional da empresa e ampliou em $74 \%$ as suas relações com a comunidade. Além disso, a produtividade e a motivação dos funcionários cresceram $34 \%$, o envolvimento dos funcionários com a empresa aumentou em $40 \%$ e a contribuição para o desenvolvimento dos conhecimentos técnicos e habilidades destes apresentou incremento 52\% (FISHER; FALCONER, 1999 apud LOURENÇO; SCHRODER, 2003, p. 17) 
Em sua Cartilha Informativa para Reconhecimento em Cultura Digital Responsável, a Fundação Orsa (2009) elenca sete dimensões de vantagens advindas do reconhecimento pela conquista do Selo Verde. Entre elas, destaca-se a dimensão sustentabilidade, na qual se afirma que os produtos ou serviços certificados ganham valor de mercado na conquista por clientes que cada vez mais prezam pela responsabilidade ambiental.

Utilizando como referência a "Pesquisa 2006-2007 - Responsabilidade Social Empresarial - Percepção do Consumidor Brasileiro", realizada pela Market Analysis Brasil, sob supervisão do Instituto Akatu pelo Consumo Consciente e do Instituto Ethos de Empresas e Responsabilidade Social, foi constatada uma diminuição na pré-disposição de punir ou premiar empresas em função de sua conduta social. Segundo outros resultados da pesquisa:

- $77 \%$ dos entrevistados têm interesse em saber como as empresas tentam ser socialmente responsáveis;

- $75 \%$ dos consumidores sabem que têm o poder de influenciar o comportamento das empresas;

- 66,5\% têm uma avaliação positiva sobre a contribuição das empresas para o desenvolvimento da sociedade;

- $51 \%$ concordam que as empresas devem contribuir ativamente com a construção de uma sociedade melhor;

- $24 \%$ disseram adquirir produtos de empresas responsáveis e fazer propagandas para a mesma como forma de premiação; e

- $27 \%$ manifestaram intenção de boicotar produtos de organizações com atuação social insatisfatória como forma de punição.

São resultados ainda tímidos, se comparados ao comportamento dos consumidores em países mais desenvolvidos, mas ao mesmo tempo animadores porque demonstram tendência de seletividade nesse novo consumidor brasileiro, agora mais exigente e consciente da sua importância.

É fato que responsabilidade social e consumo ético consciente são valores que permeiam as relações socioeconômicas em todo o mundo. Baseados nessa afirmativa, Lourenço e Schroder (2003) levantaram as principais causas de per- 
das empresariais em função de práticas rejeitadas pelos consumidores. Entre elas, destacam-se:

- A diminuição nas vendas pelo boicote à marca ou produto;

- A perda de clientes por propaganda enganosa ou falta de qualidade e segurança nos produtos;

- O pagamento de multas por desastres ambientais ou processos judiciais;

- A baixa produtividade em função da insatisfação dos funcionários; e

- O afastamento dos investidores devido à desvalorização da empresa no mercado.

Embora Fedato (2005) apresente resultado de pesquisa denotando possíveis dificuldades das empresas em correlacionar investimentos sociais com vantagens competitivas, o caráter ideológico e estratégico atribuído às ações permite afirmar que a evolução do processo de cidadania empresarial é contínua e irreversível.

\section{Considerações finais}

O aprimoramento dos processos de gestão e dos modelos de conduta responsável, voltados para o atendimento das expectativas e demandas da sociedade como um todo, e a conciliação deles com a estratégia do negócio demonstram ser procedimentos viáveis como método de gestão de negócios lucrativos, de impactos positivos e benéficos para todos os agentes envolvidos.

No ambiente corporativo brasileiro, as práticas socialmente responsáveis são cada vez mais comuns e perceptíveis no dia a dia das pessoas. O desempenho dos papéis sociais das organizações pode ser observado nos supermercados, quando eles se preocupam em diminuir o uso das sacolas plásticas; nas grandes corporações, quando patrocinam projetos voltados para a prática do esporte e quando promovem o incentivo à educação e à cultura; nas empresas que procuram minimizar no meio ambiente os danos causados por suas atividades produtivas; ou mesmo nas peças publicitárias veiculadas no rádio e na TV, onde se denota preocupação com a manutenção de condições favoráveis para a viabilidade de vida humana no Planeta Terra. 
As variadas iniciativas demonstram que as motivações para a prática de ações de RSC são de naturezas diversas, mas sempre tendo como pano de fundo, no que se refere ao mercado consumidor, a melhoria da imagem ou a obtenção de vantagens competitivas frente aos concorrentes com posturas socialmente responsáveis menos aparentes ou inexistentes.

Assim, com base na execução da pesquisa bibliográfica consubstanciada para realização deste trabalho, em resposta ao problema de pesquisa formulado, pode-se afirmar que os investimentos em responsabilidade social e o engajamento nesta nova ordem política e social proporcionam benefícios e vantagens para as organizações. A seu favor, os principais ganhos advindos da inserção das ações socialmente responsáveis à estratégica do negócio estão relacionados:

- À imagem, pelo fortalecimento da marca;

- Às vendas, em função da fidelidade ao produto;

- Ao retorno publicitário, devido à geração de mídia espontânea; e

- À produtividade, em razão da maior motivação da força de trabalho.

São contabilizados, ainda, ganhos econômicos decorrentes da existência de algumas situações de isenção de impostos e incentivos fiscais por patrocínio de projetos, especialmente nas áreas esportiva, cultural e artística, nas esferas municipal, estadual e federal. Acionistas e investidores também são contemplados com benefícios, já que se apropriam da valorização econômica da empresa na sociedade e no mercado.

No entanto, um dos maiores benefícios que abrange toda a sociedade, talvez, não possa ser mensurado financeiramente. São os ganhos advindos do desenvolvimento sociopolítico da população, da construção da cidadania, da melhoria na qualidade de vida das comunidades carentes; das mudanças comportamentais da sociedade; e da coesão e da conscientização dela para buscar a minimização dos problemas ambientais, que em longo prazo significam a manutenção das condições de sobrevivência no planeta para as gerações futuras.

O mérito deste trabalho está na contribuição para o enriquecimento do debate acerca do conceito de responsabilidade social corporativo e dos benefícios 
originados em função de sua prática por parte das organizações. Contudo, dada a amplitude do tema, observa-se que ainda há muito a ser estudado.

As principais limitações referem-se ao direcionamento da pesquisa. Como se optou por não abordar algumas dimensões relacionadas à responsabilidade social corporativa, embora se tenha citado ao longo do trabalho, de maneira superficial, os benefícios gerados para os funcionários, sugere-se para agenda futura a realização de trabalhos, buscando aprofundar o conhecimento sobre os ganhos internos das organizações, como melhoria do clima organizacional e aumento do grau de satisfação dos funcionários, assim como o índice de participação deles nas ações de voluntariado.

\section{Influence of investment in social responsibility of the image of organizations and competitive ability}

\section{Abstract}

In the twentieth century, access to information and the emergence of new technologies have enabled companies to achieve higher productivity, but the socio-economic transformations have increased the competition between them. In parallel, the weakening of the state and the aggravation of social problems has highlighted the importance of development strategies. In this context, it was realized that the disorderly exploitation of natural resources has made it mandatory to preserve the conditions of life on earth. It was felt then the need for organizations to act within moral principles and act in compliance with the law, values and interests of those affected by their actions or productive activities. Emerging paradigm of a new social order in which we prioritize activities collectivist interests to alleviate social ills. It is the emergence of social consciousness on the part of organizations, when one realizes that the disparity is detrimental to economic development. The result was an adaptation of the rational logic of the production system, inserting in it the social rationality, whose goal was to minimize the undesirable effects of globalization and systemic risk. Gradually organizations take on the status of agents of development of the first magnitude, without spoiling the role of the state and society. Management models of responsible behavior, aimed at meeting the demands of 
society, and reconciling them with the business strategy, emerge as innovative ways to achieve improvement of the image, increase market share and organizations present themselves as viable procedures for profit business management, positive impacts and beneficial for all involved.

Keywords: Social responsibility. Development. Competition. Ethical. Strategy. Image improvement. Positive impacts.

\section{Referências}

ASHLEY, P. A.; COUTINHO, R. B. G.; TOMEI, P. A. Responsabilidade social corporativa e cidadania empresarial: uma análise conceitual comparativa. In: ENCONTRO ANUAL DA ANPAD, 24., 2000, Florianópolis. Anais... Florianópolis: ANPAD, 2000. Disponível em: <http://www.agenda21empresarial.com.br/ arquivo/1260083712.375-arquivo.pdf>. Acesso em: 11 jun. 2010.

ASHLEY, Patrícia Almeida. Ética e responsabilidade social nos negócios. São Paulo: Saraiva, 2002.

CARROLL, A. B. The pyramid of corporate social responsibility: toward the moral management of organizational stakeholders. Business Horizons, New York, v. 34, n. 4, p. 39-48, jul./aug. 1991.

AS EMPRESAS mais admiradas do Brasil em 2009. Carta capital. Disponível em: $<$ http://www.cartacapital.com.br/app/materia.jsp?a $=2 \& a 2=6 \& \mathrm{i}=5314>$. Acesso em: 8 out. 2010.

CHEIBUB, Z. B.; LOCKE, R. M. Valores ou interesses?: reflexões sobre a responsabilidade social das empresas. In: KIRSCHNER, A. M.; GOMES, E. R.; CAPPELLIN, P. (Org.). Empresa, empresários e globalização. Rio de Janeiro: Relume-Dumará, 2000. Disponível em: <http://rlocke.scripts.mit.edu/ rlocke/ docs/papers/Locke,R\%20\%26\%20Cheibub,Z_Valores\%20ou\%20Interesses.pdf>. Acesso em: 14 jun. 2010.

COUTINHO, R. B. G.; MACEDO-SOARES, T. D. L. V. A. Gestão estratégica com responsabilidade social: arcabouço analítico para auxiliar sua implementação em empresas no Brasil. Revista de administração contemporânea, Curitiba, v. 6, n. 3, set./dez. 2002. Doi: 10.1590/S1415-65552002000300005. Disponível em: $<$ http://www.scielo.br/scielo.php?pid=S141565552002000300005\&script=sci 
arttext\&tlng=en>. Acesso em: 10 jun. 2010.

DAVENPORT, K. Corporate citizenship: astakeholder approach for defining corporate social performance and identifying measures for assessing it. Business and Society, v. 39, n. 2, p. 210-219, 2000

DONALDSON, t., DUNFEE, T.W. Towards a unified conception of business ethics: Integrative social contracts theory. Academy of Management Review. v.19, p. 252284, 1994.

FEDATO, Maria Cristina Lopes. Responsabilidade social corporativa: benefício social ou vantagem competitiva? 2005. 140 f. Dissertação (Mestrado)-Faculdade de Economia, Administração e Contabilidade, Universidade de São Paulo, São Paulo, 2005. Disponível em: <http://www.teses.usp.br/teses/disponiveis/12/12139/ tde-24072006-161703/pt-br.php>. Acesso em: 28 set. 2010.

FISCHER, Rosa Maria; FALCONER, Andrés Pablo. Voluntariado empresarial: estratégias de empresas no Brasil. São Paulo: Centro de Estudos em Administração do Terceiro Setor - CEATS/USP, 1999. Disponível em: <http://www.ceats.org.br >. Acesso em: 27 set. 2010.

FREEMAN, E.; LIEDTKA, J. Corporate social responsibility: acritical approach. Business Horizons, v. 34, n. 4, p. 92-97,1991.

FRIEDMAN, M. The social responsibility of business is to increase its profits. New York: Times Magazine, 1970.

FUNDAÇÃO ORSA. [Site], 2009. Disponível em: <http://www.interacaodigital. org.br/parceiros.html>. Acesso em: 28 set. 2010.

GRUPO DE INSTITUTOS FUNDAÇÕES E EMPRESAS (GIFE). [Site], 2010. Disponível em: <http://www.gife.org.br>. Acesso em: 04 out. 2010.

INSTITUTO AKATU PELO CONSUMO CONSCIENTE. Pesquisa 2006-2007: responsabilidade social empresarial - percepção do consumidor brasileiro, 2008. Disponível em: <http://www.akatu.org.br/akatu_acao/publicacoes/perfil-doconsumidor $>$. Acesso em: 17 out. 2010.

INSTITUTO BRASILEIRO DE ANÁLISE SOCIAL E ECONÔMICA (IBASE). [Site], 2010. Disponível em: <http://www.ibase.com.br>. Acesso em: 26 set. 2010.

INSTITUTO ETHOS DE EMPRESAS E RESPONSABILIDADE SOCIAL. 
Responsabilidade social empresarial para micro e pequenas empresas: passo a passo. São Paulo, 2003. Disponível em: <http://www.ethos.org.br/_Uniethos/Documents/ responsabilidade_micro_empresas_passo.pdf $>$. Acesso em: 13 set. 2010.

INSTITUTO DE PESQUISA ECONÔMICA APLICADA (IPEA). Pesquisa ação social das empresas. Brasília. Disponível em: <http://www.ipea.gov.br/acaosocial/ IMG/pdf/doc-28.pdf>. Acesso em: 27 set. 2010.

JONES, M. T. Missing the forest for the trees: a critique of the social responsibility concept and discourse. Business and Society, v. 35, n. 1, p. 7-41, 1996.

LOURENÇO, Alex Guimarães; SCHRÖDER, Débora de Souza. Vale investir em responsabilidade empresarial?: stakeholders, ganhos e perdas. Rio de Janeiro, 2003. Disponível em: <http://ethos.org.br/_Uniethos/Documents/ VALE\%20INVESTIR\%20EM\%20RESPONSABILIDADE\%20SOCIAL\%20 EMPRESARIAL\%20_.pdf $>$. Acesso em: 24 set. 2010.

MAIGNAN, Isabelle \& FERRELL, O. C. Measuring corporate citizenship in two countries: the case of the United States and France. Journal of Business Ethics, v. 23, n. 3, Feb. 2000.

MELO NETO, Francisco Paulo de; FROES, César. Gestão da responsabilidade social corporativa: o caso brasileiro. Rio de Janeiro: Qualitymark, 2001.

TIRAS, S.; RUFF, B.; BROWN, R. M. The relation between stakeholders' implicit laims and firm value. Disponível em: <http://www.ssrn.com>. Acesso em: 10 out. 2010.

TRASFERETTI, José. Ética e responsabilidade social. Campinas, SP: Editora Alínea, 2006.

WOOD JÚNIOR, Thomaz (Coord.). Gestão empresarial: oito propostas para o terceiro milênio. São Paulo: Atlas, 2001. 


\section{Para publicar na revista Universitas Gestão e TI, entre no endereço eletrônico www.publicacoesacademicas.uniceub.br. Observe as normas de publicação, facilitando e agilizando o trabalho de edição.}

